\title{
Transient hyperopia with lens swelling at initial therapy in diabetes
}

\author{
Y Saito, G Ohmi, S Kinoshita, Y Nakamura, K Ogawa, S Harino, M Okada
}

\begin{abstract}
The clinical courses of $\mathbf{1 0}$ eyes of five diabetic patients who exhibited bilateral transient hyperopia (maximum: 1.1-4.9 dioptres, spherical equivalent) after initiation of strict control of diabetes with or without insulin are reported. The hyperopia occurred within a few days after abrupt decrease in plasma glucose, progressed to maximum at days $7-14$, and regressed gradually over 1 month thereafter. Transient cycloplegia had no effect on refractive error. During hyperopia, there were no significant changes in axial length or corneal curvature. However, thickened lens, decreased anterior chamber depth, and transient cataract were observed to significant degrees. It is suggested that the transient hyperopia, with lens swelling and opacity, was caused by decreased lens refractive index following water influx.
\end{abstract}

(Br f Ophthalmol 1993; 77: 145-148)

It is known that there are refractive complications in diabetes: however, because ophthalmologists do not often encounter such phenomena, details as to clinical course and possible cause are not yet clear. There have been several observations from other contributors regarding refractive changes in diabetes, related either to increasing or decreasing blood sugar. Duke-Elder ${ }^{1}$ proposed the classical theory of myopia with increasing and hyperopia with decreasing blood glucose. Conversely, recent studies have described hyperopic change even with increasing blood glucose. $^{2-5}$ In the treatment of diabetes, with blood sugar decrease ophthalmologists occasionally observe refractive change. ${ }^{46-8}$ Caird and associates $^{6}$ reported transient hyperopia after initiation of insulin therapy in newly discovered diabetics in youth or early middle life, and Gwinup et al, ${ }^{9}$ by increasing the insulin dose, discovered hyperopia in diabetic patients who initially had relatively high glucose concentrations. Riordan Eva et $a l^{l}$ suggested that every refractive change is hyperopic, whether with

Table 1 Clinical background of present five diabetic cases

\begin{tabular}{llllllll}
\hline Cases & $M / F$ & $\begin{array}{l}\text { Age } \\
\text { (years) }\end{array}$ & $\begin{array}{l}\text { Duration of } \\
\text { DM (years) }\end{array}$ & $\begin{array}{l}\text { FPG: pre- } \\
\text { treatment }\end{array}$ & $\begin{array}{l}\text { HbA } 1 c: \text { pre- } \\
\text { treatment }\end{array}$ & DM status & Therapy \\
\hline 1 & F & 53 & ND & $17 \cdot 2 \mathrm{mmol} / 1$ & $16 \cdot 2 \%$ & NIDDM & Diet \\
2 & F & 28 & ND & $16 \cdot 6$ & $14 \cdot 9$ & IDDM & Insulin \\
3 & $M$ & 53 & ND & $16 \cdot 8$ & NA & Steroid induced & Insulin \\
4 & $M$ & 45 & ND & $16 \cdot 6$ & $13 \cdot 2$ & IDDM: post RTP & \\
5 & $M$ & 57 & 6 & $45 \cdot 7$ & $14 \cdot 3$ & NIDDM & SU \\
Mean (SD) & & $47(10)$ & & $22 \cdot 6(12 \cdot 9)$ & $14 \cdot 7(1 \cdot 3)$ & & Insulin \\
& & & & & & & \\
\hline
\end{tabular}

$\mathrm{DM}=$ diabetes mellitus; $\mathbf{F P G}=$ fasting plasma glucose; $\mathrm{HbA}_{\mathrm{lc}}=$ glycosylated haemoglobin $\mathrm{A}_{\mathrm{lc}} ;$ $\mathrm{ND}=$ newly diagnosed; NIDDM = non-insulin-dependent DM; IDDM = insulin-dependent DM; $\mathrm{NA}=$ not available; $R$ TP=renal transplantation; $\mathrm{SU}=$ sulphonyl urea; $S I$ conversion of $\mathrm{FPG}$ : $\mathrm{mg} / \mathrm{dl} \times$ $0.0555=\mathrm{mmol} / 1$ increasing or decreasing blood sugar. The present study investigated the details of hyperopic change during the treatment of diabetes, as assessed using the biometric method, and found that hyperopia was accompanied by lens swelling.

\section{Patients and methods}

The clinical backgrounds of the five patients in this study are shown in Table 1. Ranging in age from 28-57 years (average age 47 (SD 10) years), they were diagnosed as follows: two insulin dependent diabetes mellitus (IDDM), two nonIDDM (NIDDM), and one poorly controlled NIDDM of 6 years' duration. All were hospitalised and received blood sugar control for diabetes, with insulin administration, oral hypoglycaemic agents, or strict diet. At admission, average fasting plasma glucose (FPG) was 22.6 $\mathrm{mmol} / \mathrm{l}(407 \mathrm{mg} / \mathrm{dl})$. Several days after abrupt decrease of blood glucose, they experienced bilateral blurred vision, near vision disturbance or recovery from myopia.

After the first visit, all were examined at 1-3 week intervals ophthalmoscopically and by slit-lamp. Corrected visual acuity was evaluated repeatedly. After topical instillation of $1 \%$ cyclopentolate hydrochloride and $0.5 \%$ tropicamide, refraction under cycloplegia was measured by automatic refractokeratometer (ARK-2000, Nidek Co Ltd, Gamagori, Aichi, Japan). In cases of astigmatism, spherical equivalent values were used. During the follow up period, when the refraction remained unchanged for 2 or more weeks, the datum was defined as a stabilised number. Corneal curvatures were measured by automatic refractokeratometer. Intraocular pressure was measured with a non-contact tonometer ( $\mathrm{T}-2$, Canon Incorporated, Tokyo, Japan). FPG measurement and other general examinations were performed repeatedly.

Photographic biometry was performed for anterior chamber depth (ACD) and lens thickness using slit-lamp photographs (SC-1200, Kowa Optimed, Tokyo, Japan) taken under cycloplegia and standardised conditions: same angle and width of slit light, focusing at the iris under fixation. Averaged values of lens thickness and ACD were obtained from several photographs, using an image analysis system (LA-555, PIAS Co Ltd, Osaka, Japan). Firstly, we obtained working values as percentages of both lens thickness and ACD in relation to horizontal corneal diameter in the photograph; secondly, we calculated the ratio between working values of hyperopic and stabilised states. The ratio between both states was statistically analysed by paired $t$ test. Lens opacity in the photographs 

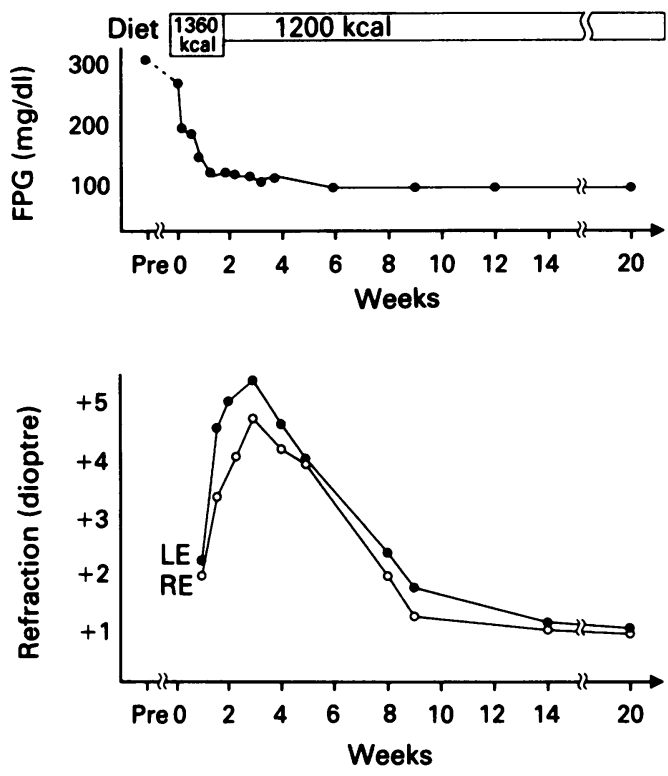

Figure 1 Case 1. Clinical course of right eye $(R E)$ and left eye $(L E) . X$-axes are the time courses, 'pre' means last measurement of fasting plasma glucose (FPG) immediately before admission. Zero point means the start of medical therapy with strict diet after admission.

was also analysed by the same system as for microdensitometry.

Ultrasonic biometry was performed for ACD, lens thickness, and axial length using A-mode scan (US-1600, Nidek Co Ltd, Gamagori, Aichi, Japan, or digital B-2000, Alcon laboratories, Fort Worth, TX, USA, for case 4; both devices have a solid probe with a $10 \mathrm{MHz}$ transducer, and a measurement accuracy is $\pm 0.04 \mathrm{~mm}$ ). Specialists not informed of this research selected reliable values during continuous one-touch measurement. Statistical analysis was performed via paired $t$ test, between both hyperopic and stabilised states of every eye. Using an infrared optometer $^{10}$ (AR3-SV14, Nidek Co Ltd, Gamagori, Aichi, Japan) cycloplegic refraction continuously measured for 160 seconds was also performed repeatedly.

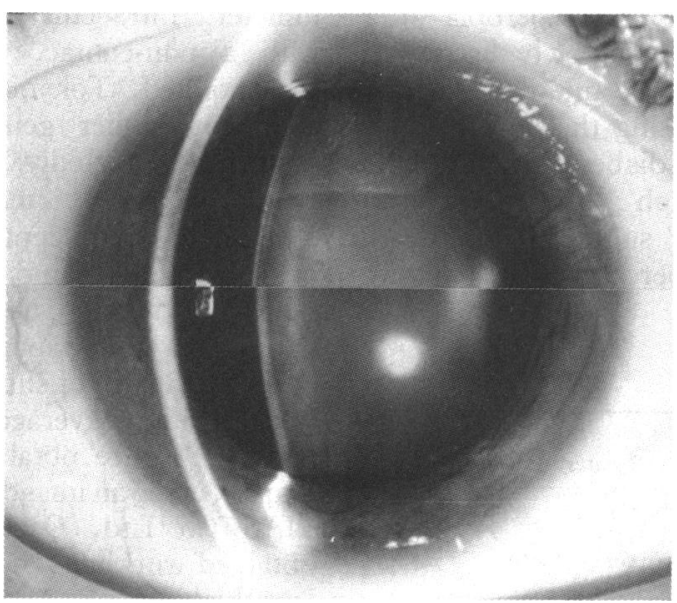

Figure 2 Case 1. Slit-lamp photographs of hyperopia (RE at third week (upper) and stabilised at 16th week (lower); lens is $9 \%$ thicker in hyperopic state; decreased nuclear opacity was observed in stabilised state. Because of slightly different width of slit light, the lower cornea appears thicker, such small change can be eliminated by calibration of the image analysis system.

\section{Case reports}

CASE 1

A 53-year-old woman (height $158 \mathrm{~cm}$, body weight $65 \mathrm{~kg}$ ) had experienced acute onset of thirst and polyuria 2 months previously. Her FPG was $17.4 \mathrm{mmol} / 1$ (313 mg/dl), glycosylated haemoglobin $A_{1 c}\left(H_{b A}\right) 16 \cdot 2 \%$. She was hospitalised for medical control of diabetes. Three days after abrupt decrease in FPG by strict diet, she experienced blurred vision; she consulted an ophthalmologist on the seventh day. Her corrected visual acuity was $20 / 20$ in both eyes. Cycloplegic refraction showed $+2 \cdot 5 \mathrm{DS}$ $-1.0 \mathrm{DC}$ at $87^{\circ}$ right eye (RE) and $+3.0 \mathrm{DS} /$ $-0.75 \mathrm{DC}$ at $25^{\circ}$ left eye (LE). Ophthalmoscopic examination showed no diabetic retinopathy. During follow up, hyperopia increased to maximum at the third week (RE: $+5.75 \mathrm{DS} /$ $-1.75 \mathrm{DC}$ at $122^{\circ}, \mathrm{LE}:+5.75 \mathrm{DS} /-0.25 \mathrm{DC}$ at $86^{\circ}$ ), with visual disturbance (R: 20/50, L: 20/20). The hyperopic change decreased gradually, ceasing after 14 weeks. The clinical course is summarised in Figure 1. Slit-lamp photographic biometry of the RE, comparing maximum hyperopia and stable state at 16 weeks, showed the lens to be $9 \%$ thinner in the later photograph, with decreased opacity observed in the stable state (Fig 2). Ultrasonic Amode scan also revealed a $0.3 \mathrm{~mm}$ decrease in lens thickness. Microdensitometry of these photographs showed a different shape of nucleus opacification (Fig 3).

\section{Results}

The clinical courses of transient hyperopic changes are shown in Table 2. After therapy started with or without insulin, blood glucose decreased abruptly. At the onset of ocular symptoms at 1 to 9 days after therapy (average 5 days), mean FPG had decreased to 7.4 (SD 2.1) $\mathrm{mmol} / \mathrm{l}$ from 22.6 (SD 12.9) $\mathrm{mmol} / 1$ at pretreatment. The hyperopia increased, developing to a maximum average of $3 \cdot 0(1 \cdot 1-4 \cdot 9)$ dioptres (spherica equivalent) after 10 (7-14) days. It took almost 2 months (mean 51 (SD 27) days) for refraction
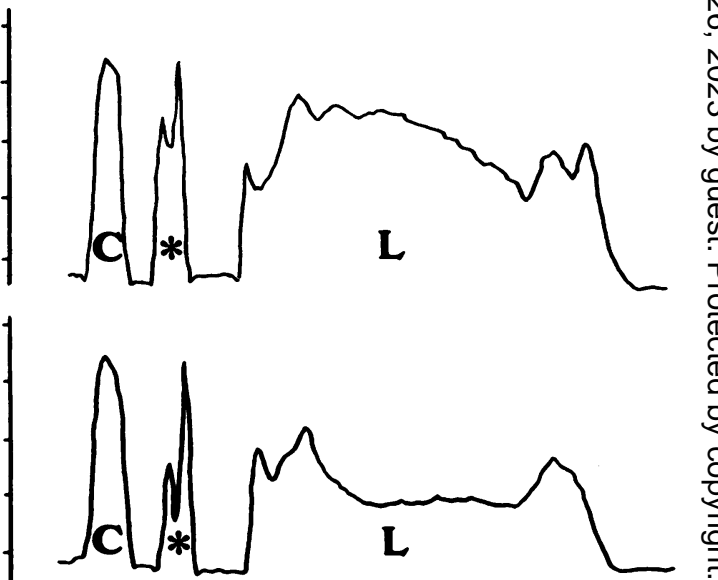

Figure 3 Case 1. Microdensitometry of lens axis in paired photographs described in Figure 2. Nuclear opacity decreased in later photograph. $\left(C=\right.$ cornea; $L=$ lens; ${ }^{*}=$ corneal reflex of flash). 
Table 2 Clinical course of transient hyperopia and cataract

\begin{tabular}{|c|c|c|c|c|c|c|}
\hline Cases & $\begin{array}{l}\text { Onset of } \\
\text { symptoms }\end{array}$ & $\begin{array}{l}\text { FPG at } \\
\text { onset }\end{array}$ & $\begin{array}{l}\text { Maximum } \\
\text { hyperopia }\end{array}$ & $\begin{array}{l}\text { Recovery } \\
\text { from } \\
\text { hyperopia }\end{array}$ & $\begin{array}{l}\text { Maximum } \\
\text { change }\end{array}$ & $\begin{array}{l}\text { Transient } \\
\text { cataract }\end{array}$ \\
\hline 1 & 4 days & $7.3 \mathrm{mmol} / \mathrm{l}$ & 14 days & 98 days & \multirow{6}{*}{$\begin{array}{l}\text { (R) } 4.6 \text { dioptre } \\
\text { (L) } 4.9 \\
\text { (R) } 4.4 \\
\text { (L) } 4.4 \\
\text { (R) } 2.6 \\
\text { (L) } 2.9 \\
\text { (R) } 1.9 \\
\text { (L) } 1.8 \\
\text { (R) } 1.5 \\
\text { (L) } 1.1 \\
3.0(1.4)\end{array}$} & \multirow{6}{*}{$\begin{array}{l}++ \\
++ \\
+ \\
+ \\
+ \\
\text { NA } \\
+ \\
+ \\
+ \\
-\end{array}$} \\
\hline 2 & 5 & $7 \cdot 4$ & 7 & 28 & & \\
\hline 3 & 9 & $4 \cdot 7$ & 14 & 49 & & \\
\hline 4 & 4 & 6.9 & 10 & 38 & & \\
\hline 5 & 1 & $10 \cdot 7$ & 7 & 42 & & \\
\hline Mean (SD) & $5(3)$ & $7 \cdot 4(2 \cdot 1)$ & $10(4)$ & $51(27)$ & & \\
\hline
\end{tabular}

Numbers of time course are counted from the start of medical therapy after admission. (FPG $=$ fasting plasma glucose; $\mathrm{NA}=$ not available. SI conversion of $\mathrm{FPG}: \mathrm{mg} / \mathrm{dl} \times 0.0555=\mathrm{mmol} / \mathrm{l}$ )

Table 3 Oculometric results of slit-lamp photographs taken under standardised conditions

\begin{tabular}{|c|c|c|c|c|c|}
\hline \multirow[b]{2}{*}{ Cases } & \multirow[b]{2}{*}{$R / L$} & \multicolumn{2}{|c|}{ Lens thickness } & \multicolumn{2}{|l|}{$A C D$} \\
\hline & & Hyperopic & Stabilised & Hyperopic & Stabilised \\
\hline \multirow[t]{2}{*}{1} & $\mathbf{R}$ & 1.09 & 1.00 & 0.96 & 1.00 \\
\hline & $\mathrm{L}$ & $1 \cdot 11$ & 1.00 & 0.89 & 1.00 \\
\hline \multirow[t]{2}{*}{2} & $\mathbf{R}$ & $1 \cdot 10$ & 1.00 & 0.96 & 1.00 \\
\hline & $\mathrm{L}$ & 1.09 & 1.00 & 0.93 & 1.00 \\
\hline 3 & $\overline{\mathbf{R}}$ & $\begin{array}{ll}1.01 \\
N A\end{array}$ & $\begin{array}{l}1.00 \\
N A\end{array}$ & $\begin{array}{l}0.89 \\
\text { NA }\end{array}$ & $\begin{array}{l}1.00 \\
N A\end{array}$ \\
\hline \multirow[t]{2}{*}{4} & $\begin{array}{l}\mathbf{L} \\
\mathbf{R}\end{array}$ & $\begin{array}{l}\text { NA } \\
1.00\end{array}$ & $\begin{array}{l}\mathrm{NA} \\
1.00\end{array}$ & $\begin{array}{l}\text { NA } \\
0.99\end{array}$ & 1.00 \\
\hline & $\mathrm{L}$ & 1.03 & 1.00 & 0.99 & 1.00 \\
\hline \multirow{2}{*}{5} & $\overline{\mathbf{R}}$ & 1.00 & 1.00 & 1.03 & 1.00 \\
\hline \multirow{2}{*}{\multicolumn{2}{|c|}{$\mathrm{p}$ Value ${ }^{\mathrm{L}}$}} & 1.01 & $1 \cdot 00$ & 0.97 & 1.00 \\
\hline & & \multicolumn{2}{|c|}{$<0.02$} & \multicolumn{2}{|c|}{$<0.05$} \\
\hline
\end{tabular}

Number is ratio between working values of hyperopic and stabilised states. Working values are percentages of both lens thickness and ACD in relation to horizontal corneal diameter in the photograph. Statistical analysis was via paired $t$ test, except fo $\mathrm{NA}$ data. ( $\mathrm{ACD}=$ anterior chamber depth; $\mathrm{NA}=$ not available)

to stabilise. Both eyes of each case showed similar shifts in refraction. In two cases (cases 3 and 5) in which refraction was measured just before the start of therapy, the difference between pretreatment and stabilised state was $0 \cdot 17$ (SD 0.13) dioptres. Temporary cycloplegia did not influence the refractive error of any eye at any observation period. Repeated examination with infrared optometer around the time of hyperopia revealed a transient and less fluctuating shift to hyperopia. During these refractive interruptions over several months' follow up, one case developed bilateral background retinopathy (case 5).

In photographic biometry under cycloplegia, lens thickness in the hyperopic state was signific-

Table 4 Oculometric results using ultrasonic A-scan

\begin{tabular}{|c|c|c|c|c|c|c|c|}
\hline \multirow[b]{2}{*}{ Case } & \multirow[b]{2}{*}{$R / L$} & \multicolumn{2}{|c|}{ Lens thickness ( $\mathrm{mm}$ ) } & \multicolumn{2}{|l|}{$A C D(\mathrm{~mm})$} & \multicolumn{2}{|c|}{ Axial length (mm) } \\
\hline & & Hyperopic & Stabilised & Hyperopic & Stabilised & Hyperopic & Stabilised \\
\hline 1 & $\begin{array}{l}\mathbf{R} \\
\mathrm{L}\end{array}$ & $\begin{array}{l}5 \cdot 0 \\
4 \cdot 8\end{array}$ & $\begin{array}{l}4 \cdot 7 \\
4 \cdot 7\end{array}$ & $\begin{array}{l}3 \cdot 1 \\
3.5\end{array}$ & $\begin{array}{l}3.4 \\
3.4\end{array}$ & $\begin{array}{l}22.7 \\
22.8\end{array}$ & $\begin{array}{l}22 \cdot 8 \\
22 \cdot 8\end{array}$ \\
\hline 2 & $\mathbf{R}$ & $\begin{array}{l}4.0 \\
4 \cdot 0\end{array}$ & $\begin{array}{l}4.7 \\
3.9\end{array}$ & 3.7 & 3.7 & 23.7 & 23.6 \\
\hline & L & $4 \cdot 1$ & 3.9 & $3 \cdot 4$ & $3 \cdot 6$ & $23 \cdot 3$ & $23 \cdot 4$ \\
\hline 3 & $\mathbf{R}$ & NA & $4 \cdot 7$ & NA & $4 \cdot 8$ & $23 \cdot 5$ & $23 \cdot 7$ \\
\hline 4 & $\underset{R}{\mathbf{L}}$ & $\begin{array}{l}\text { NA } \\
4 \cdot 6\end{array}$ & $\begin{array}{l}3 \cdot 2 \\
4 \cdot 6\end{array}$ & $\begin{array}{l}\text { NA } \\
2 \cdot 5\end{array}$ & $\begin{array}{l}3 \cdot 2 \\
2 \cdot 5\end{array}$ & $\begin{array}{l}23.9 \\
25.8\end{array}$ & $\begin{array}{l}23 \cdot 7 \\
25 \cdot 7\end{array}$ \\
\hline & $\mathbf{L}$ & 4.9 & $4 \cdot 6$ & $2 \cdot 4$ & $2 \cdot 7$ & $26 \cdot 1$ & $26 \cdot 4$ \\
\hline 5 & $\mathbf{R}$ & $4 \cdot 2$ & $4 \cdot 0$ & $3 \cdot 7$ & $3 \cdot 7$ & $23 \cdot 2$ & $23 \cdot 1$ \\
\hline $\mathrm{p}$ Value & $\mathbf{L}$ & \multicolumn{2}{|c|}{$<0.01$} & \multicolumn{2}{|c|}{ NS } & \multicolumn{2}{|c|}{ NS } \\
\hline
\end{tabular}

Statistical analysis was via paired $t$ test, except for NA data between hyperopic and stabilised states fo every eye. ( $A C D=$ anterior chamber depth; $N A=$ not available; $N S=$ not significant) antly greater than in the stabilised state. ACD in the hyperopic state was significantly shallower than in the stabilised state (Table 3). Though ultrasonic biometry showed no significant difference in ACD or axial length, lens thickness was found to be significantly greater during hyperopia (Table 4). There was no significant change in corneal curvature or intraocular pressure. Photograph comparison by microdensitometer showed transient cataract in seven out of nine eyes (Table 2), in the nuclear region. Transient mild visual loss, presumably due to cataract, was present in two eyes (Cases 1 (RE): 20/50 and 3 (LE): 20/25).

\section{Discussion}

Since morphological changes were observed in the lens during transient hyperopia, with no relation to the ciliary muscle under temporary cycloplegia, this study clearly demonstrates that transient hyperopia is promoted by the lens. Previous contributors have consistently discussed refractive change on the basis of lens alteration, not only in acute refractive change during treatment of diabetes, but also in chronic change. ${ }^{11}$ Duke-Elder ${ }^{12}$ proposed the theory that hyperopia follows previous myopia, due to osmotic flow from aqueous to lens; when there is a fall in sugar concentration, reverse osmotic flow, from lens to aqueous, induces hyperopia with alteration in the power of the lens. Meanwhile Grandström ${ }^{13}$ suggested that hydration would occur when blood sugar decreased, and that involvement of the nucleus preferentially would account for the hyperopia. During the hyperopic episode, using ultrasonic A-mode scan, Planten $e t a l^{14}$ found no significant differences in either lens thickness or position. They thought that lens refractive index might be responsible for hyperopia.

In contrast to previous reports, the present study demonstrates significant thickening of the lens correlating with the width of the refractive shift and significantly decreased ACD. In ACD biometry, photography and ultrasonic A-mode scan yielded different results. A-mode scan with a solid probe made for axial length, shows some fluctuation during operation, and is not sufficiently precise to measure ACD. Though the Scheimpflug photographic method is thought to be more convenient than conventional slit-lamp photography, ${ }^{15} 16$ highly standardised slit-lamp photography must also be reliable if it is to be used as a biometric device in limited follow up study of cases. ${ }^{17}$

When the eyeball develops hyperopia despite lens swelling, change in the refractive index should be considered. Although previous contributors discussed the refractive index, to our knowledge only Kluxen and Scholz ${ }^{15}$ reported a case with enlargement of the axial diameter of the cortex and nucleus as revealed by Scheimpflug photography during transient hyperopia. In some theoretical eye models, refractive error can be calculated based on the change in refractive index. For example, when the whole lens refractive index decreases from 1.42 to 1.40 , refractive error moves 3.2 dioptres to hyperopia in Le Grand's full theoretical eye. ${ }^{14}$ Change in overall 
refraction of the lens will depend on the independent refractive indices of its layers. Though we cannot describe the change in the refractive indices of each layer, there are some speculations based on clinical observation. Huggert ${ }^{17}$ observed blurring of the inner surface of the lens on slit-lamp examination in patients with transitory hyperopia, and suggested that there may have been smoothing of the index difference between cortex and nucleus. Planten ${ }^{18}$ showed that changes in the refractive index can be visualised by the appearance of refractive surfaces in the lenticular cortex.

Glucose entering the lens can be converted, through the action of aldose reductase, to sorbitol, which can in turn be converted, through the action of sorbitol dehydrogenase, to fructose. ${ }^{19}$ The accumulation within the lens of these substances which penetrate lens membranes poorly and are further metabolised to only a limited extent, is paralleled by an accumulation of water, producing lenticular swelling. ${ }^{20}$ The influx of water, based on the water equilibrium which results when blood sugar decreases, has been used to explain transient hyperopic change. ${ }^{14}$ It is attractive to speculate that an osmotic effect due to the accumulation of sorbitol and fructose ${ }^{21}$ could account for the present findings. Possible shallowing of the $A C D$, observed only in the present eyes, and transient cataract, ${ }^{11822} 23$ support the hypothesis that acute decrease in aqueous glucose concentration following decreased blood glucose ${ }^{24}$ promotes rapid lens hydration from the aqueous.

Meanwhile, Jacob and Dunkan, ${ }^{25}$ using frog lenses, investigated the effect of exposure to hyperosmosis and normosmosis by glucose solution. The initial response to hyperosmotic shock was a decrease in lens volume. The second response was gradual lens swelling due to the net entry of glucose and accompanying water during high glucose level. On return to normosmosis, the already swollen lens experienced hyposmotic shock and swelled still further, with further increased $\mathrm{K}^{+}$permeability. This is also an attractive model for the present findings: the results could be explained by this sorbitol-free model.

Although the above mentioned two theories consistently require lens swelling at diabetes onset, we did not observe prediabetic refraction. In four of the eyes examined at both pretreatment (high glucose level) and in the stabilised state (lower glucose level), however, only slight refractive change was observed. Further prospective investigation is necessary, to elucidāte the relationship between plasma glucose concentration and refractive error.

1 Duke-Elder S. Changes in refraction in diabetes mellitus. $\mathrm{Br} \mathcal{Y}$ Ophthalmol 1925; 9: 167-87.

2 Rosen M. Diabetes mellitus with relative hyperopia. Am $\mathcal{F}$ Ophthalmol 1956; 41: 680-1.

3 Feinblum SM. Clinical significance of refractive change in diabetes. Optometric Weekly 1972; 63: 199-206.

4 Planten JTh. Physiological optic approach of lens and cataract. Ophthalmologica 1975; 171: 249-53.

5 Varma SD, El-Aguizy HK, Richards RD. Refractive change in alloxan diabetic rabbits - control by flavonoids I. Acto Ophthalmol $(K b h)$ 1980; 58: 748-59.

6 Caird FI, Pirie A, Ramsell TG. Transient visual symptoms in diabetes. In: Diabetes and the eye. Oxford: Blackwell, 1969: $122-6$

7 Riordan Eva P, Pascoe PT, Vaughan DG. Refractive change in hyperglycaemia: hyperopia, not myopia. $\mathrm{Br} \mathcal{F}$ Ophthalmo 1982; 66: 500-5.

8 Fledelius HC. Refractive change in diabetes mellitus around onset or poorly controlled. Acta Ophthalmol $(K b h) 1987$; 65: 53-7.

9 Gwinup G, Villarreal A. Relationship of serum glucose concentration to changes in refraction. Diabetes 1976; 25 . 29-31.

10 Tsuchiya $\mathrm{K}$, Ukai $\mathrm{K}$, Ishikawa T. Concurrent recording of accommodative and pupillary responses elicited by quasistatic accommodative stimulation. Nippon Ganka Gakka Zasshi (Acta Soc Ophthalmol Fpn) 1988; 92: 336-43.

11 Fledelius HC, Miyamoto K. Diabetic myopia - is it lens induced? Acta Ophthalmol (Kbh) 1987; 65: 469-73.

12 Duke-Elder S. System of ophthalmology. London: Kimpton 1970; 5: 368-73.

13 Grandström KO. Refraktions veranderungen bei diabetes mellitus. Acta Ophthalmol (Kbh) 1933; 11: 1-161.

14 Planten JTh, Koojiman AC, de Vries B, Woldringh JJH. Pathological-optic approach of cataract and lens. Ophthalmologica $1978 ; 176: 331-4$.

15 Kluxen G, Scholz A. Scheimpflug analysis of a transient hyperopia. Klin Monatsbl Augenheilkd 1987; 191: 129-32.

16 Dobbs RE, Smith JP, Chen T, Knowles W, Hockwin O. Long-term follow-up of lens changes with Scheimpflug photography in diabetes. Ophthalmology 1987; 94: 881-90.

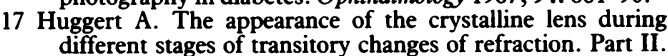
Acta Ophthalmol (Kbh) 1954; 32: 375-89.

18 Planten JTh. Changes of refraction in the adult eye due to changing refractive indices of the layers of the lens. Ophthal mologica 1981; 183: 86-90.

19 Kinoshita JH, Merola LO. Hydration of the lens during the development of galactose cataract. Invest Ophthalmol Vis $\mathrm{Sc}$ development of gal

20 Gabby $\mathrm{KH}$. The sorbitol pathway and complications of diabetes. N Engl f Med 1973; 288: 831-6.

21 Jedziniak JA, Chylack LT Jr, Cheng HM, Gillis MK, Kalustian AA, Tung WH. The sorbitol pathway in the human lens: aldose reductase and polyol dehydrogenase. Invest Ophthalmol Vis Sci 1981; 20: 314-26.

22 Brown CA, Burman D. Transient cataracts in a diabetic child with hyperosmolar coma. Brf Ophthalmol 1973; 57: 429-33.

23 Epstein DL. Reversible unilateral lens opacities in a diabetic patient. Arch Ophthalmol 1976; 94: 461-3.

24 Caird FI, Pirie A, Ramsell TG. Transient visual symptoms in diabetes. In: Diabetes and the eye. Oxford: Blackwell, 1969. $143-4$.

25 Jacob TJC, Duncan G. Glucose-induced membrane permeability changes in the lens. Exp Eye Res 1982; 34: 445-53. 